\title{
Junior high school head teachers' perceptions about their leadership styles within ejisu-juaben municipality
}

\author{
Aboagye Kwadwo Samuel, Anamuah-Mensah Jophus and Sam K. Francis \\ Department of Educational Leadership, University of Education, Winneba-Ghana
}

\section{Article Info}

Article history:

Received Oct 09, 2018

Revised Nov 13, 2018

Accepted Jan 10, 2019

\section{Keywords:}

Head teachers

Leadership styles

Perceptions

\begin{abstract}
This was a survey study aimed at finding out the perceptions of headteachers on the leadership styles of Junior High School (JHS) headteachers within the Ejisu-Juaben Municipality. The researchers selected 50 headteachers, purposively through census. A set of closed-ended questionnaire was used, and this comprised 67 items for the JHS headteacher respondents. The data was analyzed using descriptive statistics, independent t-test, and demographic analysis. The study found, among other things, that autocratic, situational and transactional leadership styles were perceived to be the predominant leadership styles practiced by the JHS heads. The study recommended, among other things, that headteachers should practice transformational and democratic leadership styles, and that the Ghana Education Service, policy makers and other stakeholders of education should strengthen the leadership component within the JHS system for effective realization of school objectives. In this respect, appointment of headship in the school setting, especially at the JHS, ought to be made in consideration of professional leadership training, aside other requirements.
\end{abstract}

Copyright $@ 2019$ Institute of Advanced Engineering and Science. All rights reserved.

\section{Corresponding Author:}

Aboagye Kwadwo Samuel, Department of Educational Leadership, University of Education, Winneba (UEW), Kumasi, Ghana; +233208150194 / +233268593456.

Email: skaboagye207@yahoo.com

\section{INTRODUCTION}

Background to the study, there are certain characteristics, demands, and roles that are expected in school leadership. These are performed based on individual styles and beliefs. For instance, the school leader is expected to perform so many functions. The school leader acts as an instructional leader to manage the nature of teaching and learning in the school; as curriculum implementer to ensure the attainment of suitable standards; as a relational expert when it comes to dealing with teachers, parents and students; and still supervising administration and management of scanty resources [1]. According to [2], school leadership goes beyond organizational leadership, since school leadership demands individualized styles.

Leadership style is any behaviour or practice of the leader exhibited in the course of playing his role as the school leader. Such leadership styles include democratic, laissez-faire, autocratic, situational, transformational, and transactional leadership styles. The extent to which schools may improve depends so much on the leadership styles employed by the school head. For instance, many scholars agree that the type of leadership style or leadership behaviour that goes with transformational leadership will help schools to change positively $[3,4]$. However, a leader may practice two, three or more styles in his or her leadership functions, depending on situations. Whatever styles a leader exhibits may be influenced by his/her sociocultural practice. School culture is defined as the prevailing atmosphere that determines the running of a school. There is a relationship between culture and leadership, based on the notion that whereas cultural norms define how organizations define leadership, leaders are thought to be experts in the creation and 
management of culture. Leaders understand and work with culture, and they are also destroyers of dysfunctional culture.

School Culture refers to not only physical or material things but also the climate or atmosphere within which school activities take place. In this study, the environment presumed to be conducive for teaching and learning, including toilet facilities, drinking water, physical classrooms and teacher support systems measure the School Culture (SC). All these are considered part of the responsibility of the school leadership. Therefore, the School leadership style (SLS) is also measured by the leadership practices, as propounded by [5], and exhibited by various heads of schools. School success also depends on the commitment level of all stakeholders of the school, which invariably affects the atmosphere for teachers and other staff to commit to their respective roles and performances. Teacher commitment, in this respect, is crucial considering the influence it exerts on teaching and learning.

Most studies, in talking about teacher commitment, dwell mostly on teacher absenteeism, lateness, contact hours, learners' support, etc. In most cases, however, the teacher performs multi-dimensional functions to keep the learning atmosphere conducive. These multi-dimensional functions include, attending to immediacy, unpredictability, and simultaneity in classroom management [6]. In this context, the teacher's ability to manage instructional delivery in a conducive, learning environment (i.e., school culture) may result from how leadership performs in the school system. Instructional delivery goes with instructional leadership in teaching and learning. Invariably, teacher commitment can affect school or academic performance; academic performance can also affect teacher commitment.

Studies have shown that school culture, teacher commitment and conditions for academic performance will depend on the style of leadership for change [7]. In other words, headteachers' leadership is responsible for creating the conditions for appropriate school culture, teacher commitment, and academic performance. Such conducive school environment promotes teaching and learning and encourages teacher commitment.

Statement of the problem, data from the GES/Statistics Services indicate that there is a great concern for schools to raise academic performance, particularly in certain subject areas, such as, Mathematics, Science, and Technology. Anamuah-Mensah and colleagues raised the alarm in a nationwide report [8] on poor performance in Integrated Science and Core Mathematics with about $60 \%$ obtaining poor grades. The same report pointed out that second year students of Junior High School (JHS2) performed poorly in international assessment such as, Trends in International Mathematics and Science Study (TIMSS). Many concerned citizens of Ejisu-Juaben Municipality have expressed a similar situation regarding education outcomes in the area. Stakeholders of education within the Ejisu-Juaben Municipality, in particular, are interested in following the trends in education, with regard to good school leadership. In this respect, gathering the views of headteachers on their leadership styles within the Ejisu-Juaben Municipality in this study could not be tagged as an exercise in futility.

Purpose, the study was to find out JHS headteachers' perceptions on their leadership styles within the Ejisu-Juaben Municipality. It had the objectives of

a. identifying the predominant leadership styles of heads of JHS within the Ejisu-Juaben Municipality;

b. highlighting the differences among demographic groups with regard to the study variables, particularly with gender groups.

The following research questions guided the study:

a. What are the predominant leadership styles of heads of JHS within the Ejisu-Juaben Municipality as perceived by the heads themselves?

b. What are the differences among demographic groups with regard to the study variables, particularly with gender groups?

Significance, the study primarily sought to add to the wealth of knowledge on the practice of school leadership. Secondly, it would help to highlight the need for leadership in basic schools, especially the junior high schools within the study area. Stakeholders in education look forward to the best schools where they can train their wards to get the best skills in life. Programmes for the professional development of principals and courses for aspiring principals may include curriculum that improves the leadership styles of headteachers. Through the research, recommendations could be made to the GES concerning appointment of heads at the basic school level. Other information that might come up through the research will provide a useful guide on future research on school leadership. Significantly, the study will contribute to educational reforms and policy-making decisions at the basic level. Finally, it will contribute to the scholarly literature on African educational systems, especially in the area of school leadership. 


\section{REVIEW OF LITERATURE}

Over the past decade, school leadership has assumed increased importance. The principal's role as a school manager has shifted toward a direct responsibility for classroom results as measured by students' academic improvement. In turn, school leaders are obligated to positively, influence the teachers to help raise students' performance. This paradigm shift generates a school-wide need to focus on school improvement. Teachers experience direct contact with students and control over content and the climate of the classroom [9]. Consequently, school heads must seek methods to raise students' achievement by adopting leadership styles that can influence teachers to help raise students' academic performance. The review specifically looks at different styles, behaviours and situations.

The choice of these styles was based on their popularity and simplicity. In addition, the researchers considered the nature of respondents, and the issues to be raised in a study at a setting such as school leadership. Specifically, the behaviour of human beings, as described in Douglas Mcregor's theory X and Y catapulted the choice of democratic and autocratic leadership styles. For laissez-faire leadership style, the views of [10] and [11] were considered. The point worthy of consideration in the choice of these leadership styles is that the respondents, who were working as salary-recipient workers, were likely to exhibit most of the characteristics described by Douglas McGregor in his theory X and Y. For transformational, transactional and situational leadership behaviours or styles, the views of a number of writers encouraged the researchers to include these leadership styles in the study. For example, the works by [12] as well as [13] are commendable. It is worthy to note that the choice of these leadership behaviours stems from the importance required (as written about by a number of authorities) to initiate and promote change in organizations, especially in educational institutions. The researchers' social background and interest in these concepts also encouraged the choice of these leadership styles and behaviours.

\subsection{Leadership Styles}

All formal organizations are established for purposes, and owners of such organizations desire that the purposes of those organizations are attained at reduced costs and with much ease [11]. In ensuring that purposes of organizations stay within attainable limits, goals have to be followed and it is through effective leadership that goals can stay focused with little or no deviations [14].

The importance of leadership within organizations requires that leaders maintain focus. This is the only way they can help steer the affairs of the organizations towards the attainment of goals. Leadership ought to acquire the necessary skills, methods and styles needed in handling various individuals within the various organizations. [10] is of the view that leadership is a craft that must be administered to achieve the mission of the organization. The question that springs up, in this respect, is, what are the styles with which leadership can operate to lead organizations to fruitfulness or attainment of goals?

\subsubsection{Democratic Leadership}

This is the type of leadership style, which is open to members of the organization for their contribution towards the running of that organization. It is worth recognizing, however, that despite this openness in democratic leadership, the leader helps his staff to operate as colleagues, collaborators, a team and partners. Here, healthy discussions lead to group decisions. This style of leadership, according to [11], is characterized by responses of co-operation, enthusiasm, acceptance of more responsibility and recognition of the worth of each worker. To Afful-Broni, the leader, here, considers himself or herself as first among equals.

The leader who practices democratic leadership style might have his beliefs stemming from Douglas McGregor's Theory Y, which shows a lot of respect to the average human being. Theory Y assumptions include the fact that people by nature: have integrity; work hard towards objectives to which they are committed; assume responsibility within commitments; desire to achieve; are capable of directing their own behaviour; want their organization to succeed; are not passive and submissive; are not stupid; and will make decisions within their commitments.

\subsubsection{Autocratic Leadership}

This type of leadership style is the direct opposite of democratic leadership in the sense that the leader here is quite domineering in his actions and decisions [11]. With this style of leadership, the leader seems to be the only dreamer whose dreams have to be forced into reality. For the realization of his dreams, according to Afful-Broni, the autocratic leader determines and sets out the policies within the organization. [14] believes that members of the organization are assigned duties without their consent. Under autocratic leadership, the leader does not entertain suggestions or initiatives from subordinates. There is little or no room for consultation. According to [11], communication is virtually non-existent, or if it exists at all in the organization, it hangs up precariously in a manner where its benefits can hardly be realized. When the leader issues directives, no individual or groups have the audacity to question but must carry out the directives. Even experts can be ignored before vital decisions are taken. This style of leadership, to [11], is characterized

Junior high school head teachers' perceptions about their leadership styles ... (Aboagye Kwadwo Samuel) 
by threats, warnings, dismissals and coercion. Views expressed contrary to those of the leader are seen as attempts to undermine or sabotage the leader. Members within an organization where this leadership style operates live in fear and intimidation. The presence and absence of the leader dictates the behaviour members of the organization put on. Afful-Broni believes that the sense of fear, uncertainties and disrespect exhibited through this leadership style has earned it other names as authoritarian, dictatorial, military, "master says" leadership and others.

Psychologists are of the view that this kind of leadership style has its roots in leaders' sense of fear and feeling of insecurity. Not much is achieved, in the absence of such leaders. Such leaders' style of leadership might stem from their entrenched belief in McGregor's Theory X, which lambasts people as naturally: lacking integrity; being fundamentally lazy and desiring to work as little as possible; avoiding responsibility; not being interested in achievements; being incapable of directing their own behaviour; being indifferent to organizational needs; preferring to be directed by others; not being very bright; and avoiding making decisions whenever possible.

\subsubsection{Laissez-faire Leadership}

What is said about democratic and autocratic leadership lends credence to the fact that the two leadership styles are at the extreme, opposing ends of the field of play for leadership styles. Between the two extreme styles could lay other leadership styles. However, lying directly in the middle of democratic and autocratic leadership styles is the type of leadership tagged, among the francophone nomenclature, as laissezfaire which means "let them do what they wish" [11], an expression which seems to emanate directly from the leader who, for reasons best known to him or her, practices this style. A person may be in a leadership position without providing clear direction, leaving the group to choose its own path in achieving aims [10]. Subordinates are given a free hand in deciding their own policies and methods of achieving the goals of such policies. In this leadership style, there are no particular rules and regulations. Absolute freedom and autonomy are bestowed on members of the organization.

\subsubsection{Conclusion}

All the leadership styles have their merits and demerits, and to a greater extent, each of them can be employed to achieve specific goals and purposes. It is worth recognizing that no one particular style can be used to do all, or to attain $100 \%$ success. In fact, the leadership styles complement each other, depending on the circumstances. Again, specific purposes and goals of an organization could direct a leader as to the best style of leadership to be used. Consideration, in this respect, ought to be taken of more leadership types (styles) like situational leadership, transformational leadership, transactional leadership, instructional leadership and so on. A blend of two or more styles of leadership may do the trick for any business-like or effective leader of an organization or any system, schools not being excluded.

\subsection{Leadership Behaviours}

There are certain behaviours that leadership will put on, depending on the circumstances and the purpose desired for achievement. In this respect, mention can be made of leadership behaviours like Transformational leadership, Transactional leadership and Situational leadership.

\subsubsection{Transactional and Transformational Leadership}

The emotional relationship between a leader and his followers is the basis of transactional leadership. [15] stated that the relations of most leaders and followers are transactional - leaders approach followers with an eye to exchanging one thing for another. [16] explains transactional theory of leadership as being focused on motivating follower through fair exchanges and by clarifying mutual responsibilities and benefits. Chemers sees this theory as implying that levels of influence rest solely on the followers' perceptions of authority and its legitimacy. In his 1996 study conducted for the U.S. Army Research Institute for the Behavioral and Social Sciences, Bass offers that transactional leadership can provide stability, structure and readiness during times of crisis or urgency [17].

Transactional leadership simply focuses on the transactions between leaders, colleagues, and followers [17]. This exchange is based on the leader discussing with others what is required and specifying the conditions and rewards. These, others will receive if they fulfill those requirements [17]. Bass also identifies what transactional leadership alone fails to do, and states that although transactional leadership provides management of emergencies with structures that have already been set up while supplying immediate needs as perceived by members, there will not be long-term positive effectiveness in coping with the stressful conditions. Transactional practices alone do nothing to grow the individual or the group toward a greater state of being or fulfillment. 
Contrarily, transformational leadership focuses on the intellectual perceptions of the leader. [15] introduced transformational leadership by identifying intellectual leaders; he explained that intellectual leaders seek to change their social milieus. He contended that the concept of intellectual leadership brings in the role of conscious purpose drawn from values. Intellectual leadership, therefore, leads us to the discovery of transforming leadership. Out of the varying motives of persons, out of the combat and competition between groups and between persons, out of the making of countless choices and the sharpening and steeling of purpose, arise the elevating forces of leadership and the achievement of intended change [17]. Transformational leadership can be seen as transactional leadership expanded to the extent that transformational leaders motivate others to do more than they originally intended and often even more than they thought possible. They set expectations that are more challenging and typically achieve higher performances [17].

[18] recognized the feelings of trust, respect and admiration towards the leader as a product of transformational leadership. He identifies three avenues of transforming and motivating followers: (1) making them more aware of the importance of task outcomes; (2) inducing them to transcend their own selfinterest for the sake of the organization or team; (3) activating their higher-order needs. Yukl describes the discovery of higher-order needs as a product of transformational leadership contrasts with the exchange, compliance product of transactional leadership. In his view, enthusiasm and commitment are common attributes of transformational leadership while transactional leadership will often provide nothing more than compliance with leader requests.

\subsubsection{Transactional and Transformational Practices in Education}

The need for balanced leadership framework can be referred to the balancing act of educational leaders to manage transactional and transformational demands. [12] analyzed the results of two studies of leadership in education. The purpose of the first study was to determine the extent to which educational leaders were perceived to use transactional and transformational leadership practices, and to determine the best predictors of leadership effectiveness through follower satisfaction. The purpose of the second study was to reveal aspects of transformational leadership that could not be explained with quantitative data [12].

Both studies discovered that extraordinarily, transformational leadership can be found in educational settings. Respondents preferred transformational practices of individualized consideration and intellectual stimulation coordinated with the transactional practice of contingent reward [12]. Extraordinary leaders also engaged in many of the task-related behaviours referred to as an initiation structure, which implies transactional leadership. It should also be noted that respondents viewed structuring activities as a necessary prelude to extraordinary accomplishments; and the initiation of structure, therefore, may provide valuable insight to identifying extraordinary leadership [12]. Our leaders took initial steps in providing resources and selecting key participants, but they were careful not to over define the structure. Instead, involvement continuously expanded. The leader's role was flexible; it was often deemphasized, as others proved increasingly capable of self-direction [12]. This realization reflects the use, by some educational leaders, of the Hersey Blanchard Situational Leadership Model for determining levels of worker maturity and leader involvement.

A vast field of literature describing leadership and the practices of effective leaders is available today. Authors define leadership as a relationship between a leader and followers. In order to build that relationship, the leader must earn the trust of the followers, articulate a vision for the organization, establish stakeholder buy-in to the vision, and rely on the strengths of others to attain set goals that agree with the vision. Leaders are responsible for learning - the learning of others as well as their own. Many agree that effective leadership is necessary if an organization is to realize success. The accountability and standards movement has caused the role of the school leader, especially the head teacher to change at a rapid pace. The responsibilities of the head teacher are challenging and demanding. He or she is accountable to all stakeholders for the success of all students.

The head teacher serves as manager, supervisor, and instructional leader, working collaboratively with teachers to ensure curriculum, instruction, and assessment correspond. High visibility, effective communication, and building community are key to effective school leadership. There is a growing recognition that leadership is distributed throughout the school community [19]. For this reason, it is necessary that head teachers recognize and promote leadership potential in others. School leaders must exhibit the leader traits of credibility, competence, positive self-regard, and authenticity. They must have high expectations for student success and serve as change agents if schools are going to meet increasing national and state standards. School leaders provide a critical bridge between reform initiatives and the positive impact these reforms can have on all students [20]. 


\subsubsection{Situational Leadership}

In this section, a review of the synthesis of leadership styles defined as situational theory was conducted to illustrate the flexibility of the principal's choices. The use of a combination of leadership styles creates a myriad of tools for the leader. Situational leadership theory presents the principal with the transformational and transactional tools to proceed in the best interest of the school that is focused on teacher effectiveness [13]. Teacher relationships with administrators are of low consideration until an internal change is implemented which requires authoritative monitoring and accountability [21]. As purveyors of situational leadership, Blanchard and Hersey depict situational leadership as less dependent on the level of management and more dependent on the maturity of the teachers supervised.

On the contrary, the acceptance of leadership behaviour flexibility that coincides with the situation is accepted as a theory, yet countered as a practice due to the dependence on the maturity of the subordinate. A study of [21] research reveals their prescriptive model of measurement of leadership style is conceptually ambiguous. It does not accurately measure the correlation between the maturity of the subordinate and the task-relevant maturity of high performance initiated by the leadership [22].

Teacher perception of school leadership as researched by [13] is determined by the situation presented. Their 1999 qualitative study focused on the analysis of the administrative leadership styles as related to teacher perception. Their pragmatic presentation of analytical data leads the reader toward an understanding of the role of the principal in a teacher-focused school environment.

Hallinger and Heck presented a caution present in situational leadership theory through their findings in a meta-analysis of 42 studies. Only after the principal establishes a culture of accountability and control, should the level of engagement change toward the transfer of leadership [23]. Nevertheless, the authors found no positive results in a school leader's push for increasing student achievement without seeking to improve teacher capacity.

Within leadership literature, the laissez-faire leadership style is the least effective style of leadership when comparing it with transformational and transactional leadership styles [24]. The avoidance or delaying of important decisions coupled with the attitude of acceptance of no change defines a laissez-faire leader [25]. Laissez-faire leadership style predictably held the most negative effect on the teachers' perceptions of global satisfaction of leadership. Teachers have a desire to be led by their school leaders [24]. Teachers who are abandoned to teach independently without knowledge or accountability to the school's mission experience a negative perception of their leader. [26] encourages the capitalization of strategies to actively engage teachers and to avoid a laissez-faire attitude through active listening, respect, the suspension of assumptions, and relating personal truths.

\section{METHODOLOGY}

There was the adoption of the descriptive research design in this study. The design was used because there was the need to identify the predominant leadership styles of the JHS headteachers within the schools selected for the study, and to achieve that, it was necessary to know the respondents' beliefs and opinions about their own leadership styles as they had observed exhibited by them (headteachers) in their respective schools. Since the information being sought in the research questions bordered on respondents' beliefs, opinions, characteristics and behaviour, it was appropriate to employ the descriptive research design. The researchers selected 50 headteachers, purposively through census. A set of closed-ended questionnaire was used, and this comprised 67 items for the JHS headteacher respondents. The researchers ensured that difficult questions were explained whenever a respondent requested for explanation, and they respectfully appealed to the respondents to be as objective as possible. In addition to this, the reliability of the questionnaire items was tested (through factor analysis and derivation of appropriate Cronbach's Alpha) after they had been coded in the computer.

\section{RESULTS AND DISCUSSION}

After the preliminary factor analysis, the researchers sought to use descriptive analysis, independent t-test, as well as demographic analysis in this study. Descriptive statistics of the study variables were highly involved in addressing the research question, "What are the predominant leadership styles of heads of JHSs within the Ejisu-Juaben Municipality as perceived by heads?" There were six variables in this respect. The descriptive statistics for variable one to six consisted of the mean scores of items related to each variable. Table 1 displays the descriptive statistics for these variables, which were related to the perceptions of JHS headteachers on leadership styles of JHS heads, within the Ejisu-Juaben Municipality. 
Table 1. Descriptive Statistics of Variables for Headteachers

\begin{tabular}{lcccccc}
\hline \multicolumn{1}{c}{ Items } & Variable 1 & Variable 2 & Variable 3 & Variable 4 & Variable 5 & Variable 6 \\
\hline Means & 2.40 & 2.02 & 3.55 & 3.69 & 2.12 & 3.81 \\
Standard Deviation & .98 & .54 & .86 & .56 & .49 & .31 \\
Variance & .96 & .29 & .74 & .31 & .24 & .09 \\
Coefficient of Variation (\%) & 41.83 & 26.73 & 24.23 & 15.22 & 23.11 & 8.142 \\
\hline Hint: Coefficient of variance calculation equals standard deviation divided by mean multiply by 100.
\end{tabular}

\subsection{Research Question 1}

From Table 1, the average mean score of (Variable 1) was 2.40, which implied that the respondents were decisive and disagreed on the existence of Democratic Leadership Style. The average mean score of (Variable 2) was 2.02, which indicated a disagreement on the existence of Laissez-faire Leadership Style. The average mean score of (Variable 3) was 3.55, an indication of some agreement on the existence of autocratic leadership style. The average mean scores of (Variables 4, 5 and 6) were 3.69, 2.12 and 3.81 respectively. In this respect, (Variable 4 and 6) indicated an agreement on the existence of situational and transactional leadership styles, but the respondents disagreed about the existence of Transformational leadership style. In answer to Research Question One, "What are the predominant leadership styles of heads of JHSs within the Ejisu-Juaben Municipality as perceived by heads?" based on descriptive statistics and coefficient of variation, the headteachers were in agreement about the finding concerning the predominant leadership styles that were practiced by the heads. These styles were autocratic, situational and transactional leadership styles. The following is a pictorial presentation of these findings.

Pictorial presentation of findings from the head teachers

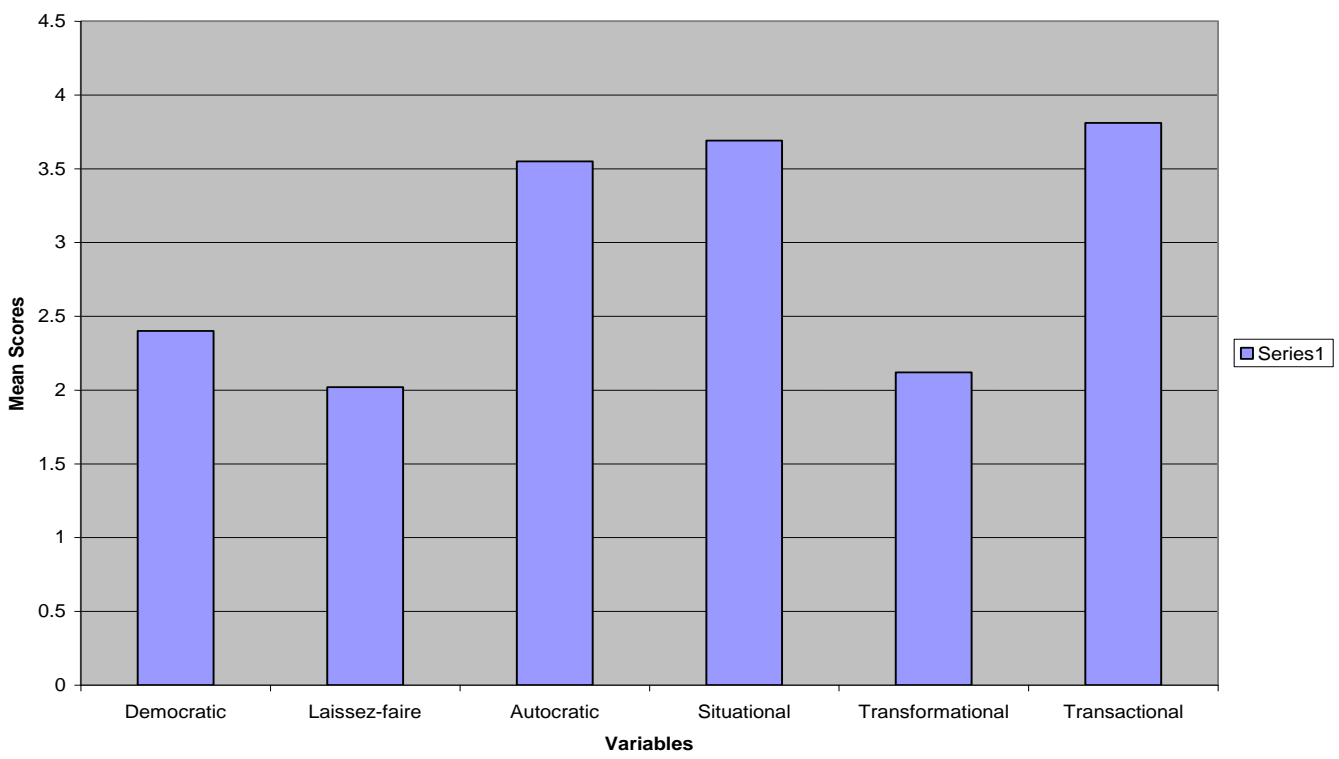

Figure 1. Histogram depicting the findings from the study about JHS headteachers' perceptions on their leadership styles.

\subsection{Demographic Information of Headteachers}

In addressing research question two, "What are the differences among demographic groups with regard to the study variables, particularly with gender groups?" the background information of the 50 headteacher respondents was considered. Of the 50 headteachers, 27 (54\%) were males and twenty-three $(46 \%)$ were females. The average age of the headteachers was calculated. For headteachers aged 30 years and below, only four were counted and this represented $8 \%$. Headteachers aged between 31 and 40 years were $21(42 \%)$. Fourteen headteachers, representing $28 \%$ were aged between 41 and 50 years. The last group of headteachers who were aged between 51 and 60 years were 11, representing $22 \%$.

The marital status of the headteachers was worked out, and it was revealed that whereas thirty-three $(66 \%)$ of them were married, seventeen $(34 \%)$ of them were singles. The educational qualification of the respondents was also checked, and the revelation was that thirteen $(26 \%)$ of them were either Diploma or 
HND holders. Whereas headteachers with Bachelor Degrees were twenty-two (44\%), those with Masters Degrees were fifteen $(30 \%)$. With the educational qualification of the headteachers known, knowledge of their ranks also became a subject of interest. The demographic information of the headteachers revealed that fourteen $(28 \%)$ of them were at the rank of Senior Superintendent. Whereas nineteen $(38 \%)$ of them were at the rank of Principal Superintendent, seventeen (34\%) of them were at the rank of either Assistant Director 2 or Assistant Director 1. However, there were no headteachers at the rank of Deputy Director of Education or Director of Education.

Experience of the headteachers was the next subject of interest to the researchers, and from the demographic information, it was revealed that fifteen $(30 \%)$ of them had been in the teaching service for between one and five years. The number of headteachers who had been in the teaching service for a period between six and ten years was eight (16\%). Six (12\%) headteachers had been in the service for a period between eleven and fifteen years. However, twenty-one (42\%) headteachers had been in the service for more than fifteen years.

\subsection{Independent t-test Analysis (Headteachers)}

The independent t-test was conducted, in respect of the headteachers, with the intention of highlighting the differences among demographic groups with regard to the study variables, particularly with gender groups. The results were found in Table 2 .

Table 2. Independent t-test Statistical Scores for Headteachers

\begin{tabular}{|c|c|c|c|c|c|c|}
\hline Variable/Gender & $\mathrm{N}$ & Mean & Standard Deviation & $\mathrm{T}$ & 2-tailed sig & $\mathrm{P}$ \\
\hline \multicolumn{7}{|l|}{$\begin{array}{l}\text { Democratic Leadership Style } \\
\text { (Variable 1) }\end{array}$} \\
\hline Male & 27 & 2.21 & 94 & -1.475 & .147 & \\
\hline Female & 23 & 2.61 & .99 & -1.469 & .149 & .922 \\
\hline Total/ Average & 50 & 2.41 & .965 & -1.472 & .148 & \\
\hline \multicolumn{7}{|c|}{$\begin{array}{l}\text { Laissez-faire Leadership Style } \\
\text { (Variable 2) }\end{array}$} \\
\hline Male & 27 & 1.98 & .56 & -.469 & .641 & \\
\hline Female & 23 & 2.05 & .52 & -.473 & .639 & .621 \\
\hline Total/ Average & 50 & 2.01 & .54 & -.471 & .640 & \\
\hline \multicolumn{7}{|l|}{$\begin{array}{l}\text { Autocratic Leadership Style } \\
\text { (Variable 3) }\end{array}$} \\
\hline Male & 27 & 3.56 & .80 & .074 & .941 & \\
\hline Female & 23 & 3.54 & .94 & .073 & .942 & 318 \\
\hline Total & 50 & 3.55 & .87 & .073 & .941 & \\
\hline \multicolumn{7}{|l|}{$\begin{array}{l}\text { Situational Leadership Style } \\
\text { (Variable 4) }\end{array}$} \\
\hline Male & 27 & 3.64 & .53 & -.650 & .519 & .685 \\
\hline Female & 23 & 3.74 & .58 & -.646 & .522 & \\
\hline Total/ Average & 50 & 3.69 & .55 & -.648 & .520 & \\
\hline \multicolumn{7}{|c|}{$\begin{array}{l}\text { Transformational leadership style } \\
\text { (Variable 5) }\end{array}$} \\
\hline Male & 27 & 2.10 & .44 & -.339 & .736 & \\
\hline Female & 23 & 2.14 & .55 & -.333 & .741 & .149 \\
\hline Total/ Average & 50 & 2.10 & .495 & -.336 & .738 & \\
\hline \multicolumn{7}{|c|}{$\begin{array}{l}\text { Transactional leadership style } \\
\text { (Variable } 6 \text { ) }\end{array}$} \\
\hline Male & 27 & 3.83 & .28 & .672 & .505 & \\
\hline Female & 23 & 3.77 & .33 & .662 & .511 & .511 \\
\hline Total/ Average & 50 & 3.80 & .30 & .667 & .508 & \\
\hline \multicolumn{7}{|l|}{$\begin{array}{l}\text { Teacher commitment } \\
\text { (Variable } 7 \text { ) }\end{array}$} \\
\hline Male & 27 & 4.09 & .41 & .147 & .884 & \\
\hline Female & 23 & 4.07 & .46 & .145 & .885 & .761 \\
\hline Total/ Average & 50 & 4.35 & .435 & .146 & .884 & \\
\hline \multicolumn{7}{|l|}{$\begin{array}{l}\text { School culture } \\
\text { (Variable 8) }\end{array}$} \\
\hline Male & 27 & 4.31 & .41 & -.512 & .611 & \\
\hline Female & 23 & 4.39 & .58 & -.499 & .621 & .250 \\
\hline Total/ Average & 50 & 4.35 & .49 & -.505 & .616 & \\
\hline \multicolumn{7}{|l|}{$\begin{array}{l}\text { Performance Improvement } \\
\text { (Variable 9) }\end{array}$} \\
\hline Male & 27 & 4.12 & .34 & .480 & .633 & \\
\hline Female & 23 & 4.07 & .46 & .470 & .641 & .312 \\
\hline Total/Average & 50 & 4.09 & .50 & .475 & .637 & \\
\hline
\end{tabular}




\subsection{Research Question 2}

From the t-test analysis, in answer to research question two, "What are the differences among demographic groups with regard to the study variables, particularly with gender groups?" it was observed that the variances for the two groups were the same for all the variables. This was so because the significant values $(\mathrm{P})$ for all the variables from Table 2 were as follow: .922, .621, .318, .685, .149, .511 respectively. The implication is that the assumption of equal variance was not violated for all the variables. From Table 2 , the significant (2-tailed) values were $.148, .640, .941, .520, .738, .508$ for the six variables respectively, which implied that there was no statistically significant difference in the mean score for all the six variables against gender for each of the two groups (male and female).

\section{CONCLUSION}

Based on the descriptive statistics and coefficient of variation, the headteacher respondents were in agreement about their perceptions concerning the predominant leadership styles that were practiced by them (JHS headteachers) within the Ejisu-Juaben Municipality. These styles were autocratic, situational and transactional leadership styles. Based on the Independent t-test for headteachers, (Table 2), the significant (2tailed) values were $.941, .520, .148, .640, .508, .739$ for the six variables respectively, which implied that there was no statistically significant difference in the mean score for all the six variables against gender for each of the two groups (male and female).

\section{REFERENCES}

[1] Sergiovanni, T. J., The principalalship: A reflective practice perspective, 6th ed, Boston: Allyn and Baacon, 2001.

[2] Snowden, P. E., and Gorton, R. A., School leadership and administration: important concepts, case studies, and stimulations, 6th ed, New York: McGraw-Hill, 2002.

[3] Barnett, K., and McCormick, J., "Leadership and individual principal-teacher relationships in schools. Educational Administration Quarterly," vol. 40, no. 3, pp. 406-434, 2004.

[4] Edwards, A. K., \& Aboagye, S. K, "Assessing school leadership challenges in Ghana, using leadership practices inventory," International Journal of Education and Practice, "vol. 3, no. 4, pp. 168-181, 2015.

[5] Kouzes, J., and Posner, B. Z. The leadership challenge: How to make extraordinary things happen in organizations, 5th ed, San Francisco, CA: Jossey-Bass, 2012.

[6] Arends, R. I., Learning to teach, New York: McGraw Hill, Inc. 1994.

[7] Ghana Education Service, Leadership for change: A handbook for Ghana education service management staff, Accra: Teacher Education Division, 2014.

[8] Ministry of Education Ghana, Report on basic statistics and planning parameters for colleges of education in ghana 2012/2013, Accra, 2014.

[9] King, M. B., and Newmann, F. M., "Accountability and school performance: Implications from restructuring schools," Harvard Educational Review, vol. 67, pp. 41-74, 2001.

[10] Berkley, J., Leadership handbook of management and administration, Grand Rapids, Mich.: Baker Books, 2004.

[11] Afful-Broni, A., Theory and practice of educational leadership in Ghana, Ghana: Type Company Limited. 2004.

[12] Kirby, P., King, M., and Paradise, L., "Extraordinary leaders in education: Understanding transformational leadership," Journal of Educational Research, vol. 85, no. 5, pp. 303-311,1992.

[13] Blase, J., and Blase, J., "Principals' instructional leadership and teacher development: teachers' perspectives. Educational Administration Quarterly," vol. 35, no. 3, pp. 349-378, 1999.

[14] Covey, S.R., Principle-centered leadership, New York: Summit Books, 2004.

[15] Burns, J. M., Leadership. New York: Harper \& Row, 1978.

[16] Chemers, M., An integrative theory of leadership, London: Lawrence Erlbaum Associates, Publishers, 1997.

[17] Bass, B. M., "From transactional to transformational leadership: Learning to share the vision," Organizational Dynamics, vol. 18, no. 3, pp. 19-31, 1990.

[18] Yukl, G., Leadership in organizations, 8th ed, Upper Saddle River, NJ: Pearson/Prentice Hall, 2013.

[19] Copland, M. A., "The myth of the super principal," Phi Delta Kappan, vol. 82, no. 7, pp. 528-533, 2001.

[20] Leithwood, K., and Jantzi, D., "A review of transformational leadership research. Leadership and Policy in Schools," vol. 4, no. 3, pp. 177-199, 2004.

[21] Blanchard, K., and Hersey, P., Management of organizational behaviour: Utilizing human resources, Englewood Cliffs, NJ: Prentice-Hall Inc., 1979.

[22] Graeff, C. L., Evolution of situational leadership theory: A critical review, USA: Illinois State University, 1983.

[23] Hallinger, P., and Heck, R., "Exploring the principal's contribution to school effectiveness: 1980-1995," School Effectiveness and School Improvement, vol. 9, no. 2, pp. 157-191, 1998.

[24] Barnett, H., Craven, R., and Marsh, A., "What type of school leadership satisfies teachers? A mixed method approach to teachers' perceptions of satisfaction," Australian Association for Research in Education, 2005.

[25] Avolio, B., and Bass, B., Multifactor leadership questionnaire: Third edition manual and sampler set, Menio Park, CA: Mind Garden, Inc., 2003.

[26] Glover, T. A. "School based screening: A population based approach," Journal of School Psychology, vol. 45, no. 2, pp. 111-264, 2007. 